\title{
Serum 25-Hydroxyvitamin D Deficiency in Ischemic Stroke and Subtypes in Indian Patients
}

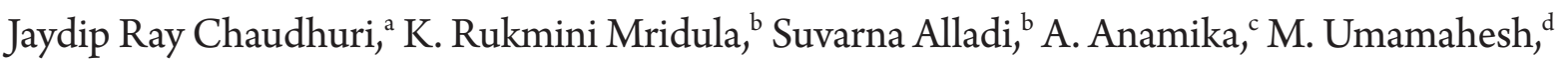 \\ Banda Balaraju, ${ }^{e}$ A. Swath, ${ }^{a}$ VCS Srinivasarao Bandaru ${ }^{\mathrm{a}, \mathrm{f}}$

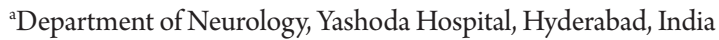 \\ ${ }^{b}$ Department of Neurology, Nizam's Institution of Medical Sciences, Hyderabad, India \\ 'Department of Biochemistry, Yashoda Hospital, Hyderabad, India \\ ${ }^{\mathrm{d}}$ Department of Radiology, Yashoda Hospital Hyderabad, India

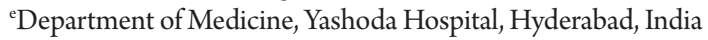 \\ ${ }^{\mathrm{f}}$ Department of Clinical Research, Yashoda Hospital, Hyderabad, India
}

Background and Purpose Vitamin D deficiency is common across all age groups and may contribute to cardiovascular diseases. Serum 25-hydroxyvitamin D deficiency causing ischemic stroke has been documented in recent reports.

Aim To investigate the association of serum 25-hydroxyvitamin D deficiency with ischemic stroke and subtypes.

Methods We recruited 250 consecutive ischemic stroke patients and 250 age and sex matched controls attending the Department of Neurology, at Yashoda hospital, Hyderabad, India, from January 2011 to December 2012. All ischemic stroke patients underwent stroke subtyping. We measured 25-hydroxyvitamin D by chemiluminescence test, serum calcium, phosphorus, alkaline phosphatase, and C-reactive protein (CRP) in cases and controls.

Results Out of 250 stroke patients, $190(76 \%)$ were men and mean age was $58.4 \pm 11.1$ years (age range-26-89 years). 25-hydroxyvitamin $D$ deficiency was observed in 122 (48.8\%) stroke patients and $79(31.6 \%)$ controls $(P=0.001)$. Among stroke patients, serum 25 -hydroxyvita$\min \mathrm{D}$ deficiency was found in 54.9\% (50/91) of patients with large artery atherosclerosis, $54 \%(20 / 37)$ in cardioembolic stroke, 44.4\% (20/45) in small artery diseases, 42.8\% (15/35) in stroke of other determined etiology and 40.4\% (17/42) in stroke of un-determined etiology. Multiple logistic regression analysis showed an independent association of 25-hydroxyvitamin D deficiency with ischemic stroke (odds ratio: 1.6; 95\% $\mathrm{Cl} 1.2-2.8$ ). The association was strongest with large artery atherosclerosis (odds ratio: $2.4 ; 95 \% \mathrm{Cl} 1.6-3.5$ ) and cardioembolic stroke (odds ratio: $2.0 ; 95 \% \mathrm{Cl} 1.0-3.2$ ).

Conclusions We found that 25-hydroxyvitamin D deficiency had an independent association with ischemic stroke. The association was established in large artery arthrosclerosis and cardioembolic stroke.

\author{
Correspondence: \\ VCS Srinivasarao Bandaru \\ Department of Neurology and Clinical \\ Research, Yashoda hospital, Hyderabad \\ -500082 , India \\ Tel: +9109441266519 \\ Fax: +91040-23370655 \\ E-mail: rsbhandaru@gmail.com
}

Received: October 4, 2013

Revised: November 25, 2013

Accepted: November 28, 2013

The authors have no financial conflicts of interest.

Keywords Ischemic stroke; Stroke subtypes; 25-hyderoxyvitamin D; Indian patients

\section{Introduction}

Stroke is a sudden onset of focal neurological deficit, a major cause of morbidity and mortality and the second leading cause of death worldwide. ${ }^{1}$ Stroke has a heterogeneous etiology, caused by modifiable and un-modifiable risk factors. Recent studies 
have strongly suggested an association of deficiency of 25-hydroxyvitamin $\mathrm{D}$ with ischemic stroke ${ }^{2,3}$ and cardiovascular disease. $^{4,5}$

Vitamin D is a 9,10 -seco steroid and the most common forms in humans are vitamin D3 (cholecalciferol) and Vitamin D2 (ergocalciferol). ${ }^{2}$ Vitamin $\mathrm{D}$ is essential for the human body to maintain a balance between calcium and phosphorus. Inadequate vitamin $\mathrm{D}$ can cause weakness, reduced bone mineralization, increased bone loss and hip fracture ${ }^{6}$ and its prevalence is high in both hemispheric populations. ${ }^{7}$ Serum 25 -hydroxyvitamin $\mathrm{D}$ is the circulating form of vitamin $\mathrm{D}$ with a half life of 2 to 3 weeks and is converted to the active form -1,25-dihydroxy vitamin D3 in the kidneys. ${ }^{8} 25$-hydroxyvitamin D is a marker of vitamin $\mathrm{D}$ status in the human body. ${ }^{9,10}$ Some population based studies have shown that $40 \%-45 \%$ of Indians have 25 -hydroxyvitamin D deficiency in India. ${ }^{11}$ We aim to investigate the association between serum 25-hydroxyvitamin $\mathrm{D}$ deficiency and ischemic stroke and its subtypes in Indian patients. There is no study, so far, on the association of serum 25-hydroxyvitamin D deficiency with increased risk of stroke in Indian patients.

\section{Methods}

Two hundred fifty patients with ischemic stroke enrolled consecutively in Yashoda hospital, which is a major referral center in the state of Andhra Pradesh. Two hundred fifty age and sex matched controls were recruited from healthy volunteers with no prior history of stroke or transient ischemic attacks. This cohort consisted of patient attendees and people volunteering for blood donation. The study period was between January 2011 and December 2012. This study is a part of ReVDAS (Role of 25-hydroxvitamin D in Acute Ischemic Stroke) study. This study was approved by the Institutional Ethics Committee and informed consent was obtained from controls and patients and if patients were severely ill, consent was taken from their relatives.

\section{Selection of cases}

Stroke patients met the following criteria: first ischemic stroke, admitted within 7 days of stroke onset. Stroke was defined according to the World Health organization as "rapidly developing clinical signs of focal/global disturbance of cerebral function, with no apparent cause other than of vascular origin." ${ }^{, 12}$ Cerebral infarction was diagnosed on the basis of the first Computer tomography (CT) or Magnetic Resonance Imaging (MRI) brain scan. If patients had a normal CT scan brain, then ischemic stroke was diagnosed based on diffusion weighted MRI.

\section{Stroke subtype analysis}

All stroke patients underwent CT scan of brain (to rule out hemorrhagic stroke) initially, followed by MRI of brain. Magnetic Resonance Angiography (MRA), Transthoracic echocardiography (TTE) or Transesophageal echocardiography (TEE), non-invasive vascular imaging (Carotid Doppler) were done in all patients. Ischemic stroke subtypes were classified as large artery atherosclerosis, cardioembolic stroke, small vessel disease (lacunar stroke), stroke of other determined etiology and stroke of undetermined etiology. ${ }^{13}$ If the etiology was not clear, then additional tests-serum fibrinogen, antithrombin III, protein C, protein $\mathrm{S}$, antinuclear and anticardiolipin antibodies were also done. Lipid profile and serum homocysteine estimation were done in all patients.

Standardized questions were modified from the behavioral risk factor surveillance system, ${ }^{14}$ by the Centers for Disease Control and Prevention. Height, weight, and blood pressure were measured, fasting blood samples were collected to estimate blood glucose, serum lipid profiles, calcium, phosphorus, alkaline phosphatase and C-reactive protein (CRP) for cases and controls.

Definition for hypertension by JNC VII (Joint National Committee) -defined as a systolic blood pressure $>140 \mathrm{mmHg}$ and/ or a diastolic blood pressure $>90 \mathrm{mmHg}$ based on the average of 2 blood pressure measurements at the time of admission, or a patient's self-reported history of hypertension or antihypertensive use, supported by documents. ${ }^{15}$ Diabetes was diagnosed if fasting plasma glucose was $>110 \mathrm{mg} / \mathrm{dL}$ or patient was on antidiabetic medications. ${ }^{16}$ As per guidelines of National Institute of Health (NIH), patients with serum cholesterol levels $>200$ $\mathrm{mg} / 100 \mathrm{~mL}$ or those on anticholesterol medication were considered as having hypercholesterolemia. ${ }^{17}$ Smokers were defined as those reporting daily smoking. Ex-smokers and occasional smokers were classified as nonsmokers. ${ }^{18}$ Alcoholics were defined as those in whom the alcohol consumption was $>50$ $\mathrm{g} /$ day (equivalent to $500 \mathrm{~mL}$ [2 drinks] of wine, $1,000 \mathrm{~mL}$ of beer, or N5 drinks [units] of spirits). ${ }^{19}$ Body Mass Index (BMI) values from 25.0-30.0 were taken as overweight and $\mathrm{BMI}$ values $>30$ were taken as obese. ${ }^{20}$

\section{Blood collection}

Blood collection was done at the time of enrollment of cases and controls; $5 \mathrm{~mL}$ blood sample was used for estimation of 25-hydroxyvitamin D. We used chemiluminescent microparticle immunoassay (CMIA) with automated instruments for estimation of 25 -hydroxyvitamin D. Values $\leq 20 \mathrm{ng} / \mathrm{mL}$ were diagnosed as 25-hydroxyvitamin D deficiency. ${ }^{10,21,22}$ Values from 11$20 \mathrm{ng} / \mathrm{mL}$ were considered mild and $<10 \mathrm{ng} / \mathrm{mL}$ were diag- 
nosed as severe vitamin $\mathrm{D}$ deficiency.

\section{Statistical analysis}

Statistical analysis was performed using SPSS 14.0 software (Chicago, IL, USA). Mean +SD (Stranded Deviation) were calculated. The paired ' $\mathrm{t}$ ' test was applied to test the differences in continuous variables and McNemar test was applied to study the association in proportions. We estimated odds ratio (OR) and the resulting $95 \% \mathrm{CI}$ for the matched case-control pairs. Multiple logistic regression was performed before and after adjustment for potential confounders -age, gender, hypertension, diabetes, smoking, alcoholism, hyperlipidemia and obesity. All tests were two sided and $P$ value $<0.05$ were considered statistically significant

\section{Results}

Out of 250 subjects, men were 190 (76\%), mean age was $58.4 \pm 11.1$ years (age range - 24-89 years). Hypertension was significantly more common in stroke patients (144 [57.6\%]) compared to controls $(40[26.6 \%] ; P<0.0001)$ as was diabetes (74 [49.3\%] of stroke patients vs. 31 [24\%] controls; $P<0.0001$ ). Positive CRP was noted in 156 (62.4\%) stroke patients while seen only in $83(33.3 \%)$ controls $(P<0.0001) .25$-hydroxyvitamin $D$ deficiency was more prevalent in stroke patients $22[48.8 \%])$ than controls $79(31.6 \%)$ which was statistically significant $(P=$ $0.0001)$. Significantly decreased mean serum calcium $(8.8 \pm 2.6)$ $(\mathrm{mg} / \mathrm{dL})$ and phosphorus $(3.6 \pm 1.6)(\mathrm{mg} / \mathrm{dL})$ levels were found in stroke patients compared to controls. Mean alkaline phosphatase level was significantly increased in stroke patients $(112.1 \pm$ 38.6) $(\mu / \mathrm{L})$ compared to controls $(85.5 \pm 21.5)(\mu / \mathrm{L})(P<0.0001)$ (Table 1).

We subdivided the 25-hydroxyvitamin $\mathrm{D}$ deficiency group into mild (10.1-20.0 ng/mL) and severe deficiency (below 10 $\mathrm{ng} / \mathrm{mL}$ ) in stroke patients and controls. We found significantly higher proportions in stroke patients, of both mild (65 [26\%] vs. 45 controls [19.6\%], $P=0.002)$ and severe 25 -hydroxyvita$\min \mathrm{D}$ deficiency (57 [22.8\%] vs. 34 controls [12\%], $P=0.02$ ).

We compared the values of samples taken during summer (samples were collected from March to September) and winter (samples were collected from October to February). There were no significant differences in prevalence of 25-hydroxy vitamin $D$ deficiency between summer and winter samples in cases $(P=$ $0.5)$ and controls $(P=0.3)$ (Table 2). But in both the seasons the prevalence of 25 -hydroxyvitamin $\mathrm{D}$ deficiency was significantly higher among stroke patients compared to controls $(<0.02)$.

Among stroke subtypes, 25-hydroxyvitamin D deficiency was present in 50 patients $(54.9 \%)$ with large artery atherosclerosis, 20 patients (54\%) with cardioembolic stroke, 20 patients (44.4\%) with small artery disease, 15 patients (42.8\%) with stoke of other determined etiology and 17 patients (40.4\%) with stroke of un-determined etiology.

In the 20 patients with cardioembolic stroke and 25 hydroxyvitamin $\mathrm{D}$ deficiency, the underlying cardiac disease was varied and included history of myocardial infarction (4 patients), atrial fibrillation ( 3 patients) congestive heart failure ( 4 patients), akinetic left ventricular segment ( 2 patients ) ascending aorta ste-

Table 2. Seasonal variation of 25-hydroxyvitmain D deficiency in patients and controls

\begin{tabular}{lcc}
\hline Seasonal & $\begin{array}{c}\text { 25-hydroxy vitamin D } \\
\text { deficiency in stroke patients }\end{array}$ & $\begin{array}{c}\text { 25-hydroxy vitamin D } \\
\text { deficiency in controls }\end{array}$ \\
\hline Summer $(n=280)$ & $66 / 140(47.8 \%)$ & $42 / 140(30 \%)$ \\
winter $(n=220)$ & $56 / 110(50.1 \%)$ & $37 / 110(33.6 \%)$ \\
$P$ value & 0.55 & 0.37
\end{tabular}

Table 1. Baseline characteristics

\begin{tabular}{|c|c|c|c|}
\hline Parameters & Stroke patients $(n=250)$ & Controls subjects $(n=250)$ & $P$ value \\
\hline Men & $190(76 \%)$ & $190(76 \%)$ & \\
\hline Mean age years & $58.4 \pm 11.1$ & $58.4 \pm 11.5$ & \\
\hline Age range years & 24-89 & 24-89 & \\
\hline Hypertension & $144(57.6 \%)$ & $52(20.8 \%)$ & $<0.00001$ \\
\hline Diabetes & $126(50.4 \%)$ & $56(22.2 \%)$ & $<0.00001$ \\
\hline Smokers & $87(34.8 \%)$ & $75(30 \%)$ & 0.07 \\
\hline Alcoholics & $74(29.6 \%)$ & $70(28 \%)$ & 0.71 \\
\hline Hypercholesterolemia & $90(36 \%)$ & $78(31.2 \%)$ & 0.12 \\
\hline Obesity & $10(4 \%)$ & $3(1.2 \%)$ & 0.07 \\
\hline Serum 25-hydroxyvitamin D deficiency & $122(48.8 \%)$ & $79(31.6 \%)$ & 0.00011 \\
\hline C-Reactive Protein positive & $156(62.4 \%)$ & $83(33.2 \%)$ & $<0.00001$ \\
\hline Mean serum calcium (mg/dL) & $8.8 \pm 2.6$ & $9.4 \pm 2.3$ & 0.03 \\
\hline Mean serum phosphorous (mg/dL) & $3.6 \pm 1.8$ & $4.7 \pm 0.5$ & $<0.00001$ \\
\hline Mean alkaline phosphatase ( $\mu / L)$ & $121.1 \pm 36.6$ & $89.3 \pm 23.5$ & $<0.00001$ \\
\hline
\end{tabular}


Table 3. Univariate and multivariate analysis of various risk factors with stroke

\begin{tabular}{lcccccc}
\hline & \multicolumn{2}{c}{ Univariate } & & \multicolumn{2}{c}{ Multivariate } \\
\cline { 2 - 3 } \cline { 6 - 7 } & ORs & $95 \%$ Cls & & ORs & $95 \%$ Cls \\
\hline Hypertension & 5.1 & $3.4-7.6$ & & 4.5 & $2.5-6.1$ \\
Diabetes & 4.5 & $2.3-6.9$ & & 3.8 & $2.1-5.1$ \\
Serum 25-hydroxyvitamin D deficiency & 2.0 & $1.4-2.9$ & & 1.6 & $1.2-2.8$ \\
Smoking & 1.5 & $0.8-1.8$ & & 1.1 & $0.6-1.4$ \\
Alcoholism & 1.0 & $0.7-1.5$ & & 0.7 & $0.5-1.1$ \\
Hypercholesterolemia & 1.3 & $0.9-1.7$ & & 1.0 & $0.7-1.5$ \\
\hline
\end{tabular}

nosis ( 2 patients), mitral valve stenosis ( 2 patients), and rheumatic heart disease ( 3 patients).

On comparing the risk factors with stroke, univariate analysis demonstrated maximum risk with hypertension and diabetes followed by 25 -hydroxyvitamin D deficiency. 25-hydroxyvitamin $D$ deficiency showed an independent association with ischemic stroke (Table 3).

On evaluation of stroke subtypes 25-hydroxyvitamin D deficiency was independently association with large artery atherosclerosis and cardioembolic stroke (Table 4).

\section{Discussion}

In our study, we found a significant association between 25 hydroxyvitamin D deficiency and ischemic stroke and established an independent association. Similar results have been found from the western part of the world. ${ }^{2,3,23-26}$ We noted deficiency of 25 -hyroxyvitamin D in $54.9 \%$ of stroke patients with large artery atherosclerosis. A similar association of hypovitaminosis $\mathrm{D}$ with large artery atherosclerosis and small artery disease has been described earlier. ${ }^{25} \mathrm{~A}$ recent study showed low 25-hydroxyvitamin $\mathrm{D}$ was significantly associated with increasing intimal media thickness and carotid plaques in individuals. ${ }^{27}$ We also found a significant association of 25-hyroxyvitamin D deficiency with cardioembolic stroke. Several studies have shown a strong association of vitamin $\mathrm{D}$ deficiency with cardiovascular disease. ${ }^{28-30}$ Giovannucci et al. ${ }^{31}$ demonstrated low levels of 25hydroxyvitamin $\mathrm{D}$ as a high risk factor for myocardial infarction. Lower 25-hydroxyvitamin D concentration was shown to be an independent risk factors for atherosclerosis, coronary calcification $^{32}$ and cardiovascular death. ${ }^{33}$ However some studies have found no association between vitamin D and cardiovascular disease. ${ }^{34,35}$

The mechanism of deficiency of vitamin $\mathrm{D}$ and atherosclerosis is not fully understood. Li et al. ${ }^{36}$ observed that vitamin D regulated blood pressure by suppressing the renin angiotensin system. Aihara et al. ${ }^{37}$ demonstrated vascular effects of vitamin $\mathrm{D}$ with inhibition of thormobosis ${ }^{38}$ and reduction in arterial
Table 4. Univariae and multivariate analysis of the relationship between various stroke subtypes and serum 25-hydroxyvitamin D deficiency

\begin{tabular}{lcccccc}
\hline & \multicolumn{2}{c}{ Univariate } & & \multicolumn{2}{c}{ Multivariate } \\
\cline { 2 - 3 } \cline { 6 - 7 } & ORs & $95 \% \mathrm{Cls}$ & & ORs & $95 \% \mathrm{Cls}$ \\
\hline large artery atherosclerosis & 3.1 & $2.5-4.1$ & & 2.4 & $1.6-3.5$ \\
Cardioembolic stroke & 2.5 & $1.7-3.7$ & & 2.0 & $1.0-3.2$ \\
Small artery disease & 1.5 & $0.9-2.0$ & & $*$ & $*$ \\
Stroke of other determinate etiology & 1.3 & $0.7-2.1$ & & $*$ & $*$ \\
Stroke of indeterminate etiology & 0.9 & $0.8-1.5$ & & $*$ & \\
\hline
\end{tabular}

*Number of patients insufficient for statistical analysis.

calcification. ${ }^{39}$ In addition smooth muscle cells and lymphocytes express receptors for vitamin $\mathrm{D}$ and convert circulating 25-hydroxyvitamin D to 1,25-dihydroxyvitamin D. 1,25-hydroxy vitamin $\mathrm{D}$ in turn reduce the proliferation of lymphocytes and the production of cytokines. ${ }^{39,40}$ This anti- inflammatory effect may have a protective role as there is increasing evidence that systemic inflammation leads to atherosclerosis. ${ }^{41}$

In our study we also observed significantly higher proportion of stroke patients with elevated levels of alkaline phosphatase and decreased phosphate levels compared with control subjects. This is advocated by Nibet et al. ${ }^{42}$ and Preece et al. ${ }^{43}$ Decreased serum phosphate and increased alkaline phosphatase are caused by Vitamin D deficiency. ${ }^{44,45}$ Alkaline phosphatase may contribute to atherosclerosis by promoting vascular calcification. Elevated alkaline phosphatase has also been shown to be an independent predictor of mortality after ischemic stroke. ${ }^{46}$

$\mathrm{CRP}$ an inflammatory marker and an independent risk factor for acute ischemic stroke. ${ }^{47,48}$ In our study we found significant association deficiency of 25-hydroxyvitamin $\mathrm{D}$ with CRP positive in stroke patients compared to controls. Recent studies have advocated that CRP levels are elevated in deficiency of vitamin D. ${ }^{31}$ This furthers emphasizes the role of vitamin $\mathrm{D}$ in reducing inflammation and thus reducing atherogenesis.

The strength of this study is that both cases and controls were collected from a single center with same ethnic background and 25-hydroxyvitamin D analysis was done in one lab. We have also analyzed the association of 25 -hydroxyvitamin $\mathrm{D}$ deficiency with stroke subtypes.

Age may impact vitamin D levels. Gillor et al found that with increasing age 25 -hydroxyvitamin $\mathrm{D}$ decreases, ${ }^{49}$ as capability of skin to produce pre-vitamin D after ultraviolet (UV) B irradiation declines with age. ${ }^{50}$ In our study this effect is nullified as both cases and controls were age and sex matched.

We did not perform seasonal adjustment for vitamin $\mathrm{D}$ levels, as in our study. we did not find any significant difference between levels during winter and summer. Similar results were found in healthy subject in previous studies from India. ${ }^{51,52}$ This differ- 
ence from west may be due to the fact that as a tropical country the temperature fluctuations are \pm 10 degrees centigrade and may not impact vitamin $\mathrm{D}$ levels.

\section{Conclusions}

This study established that deficiency of 25-hydroxyvitamin $D$ had an independent association with ischemic stroke- especially large artery atherosclerosis and cardioembolic stroke. A single serum measurement of this compound could be a useful marker in epidemiologic studies. The role of vitamin D deficiency as a direct causative factor of stroke has to be established for advocating vitamin D usage for stroke prevention. Large scale interventional studies are required to confirm these findings.

\section{Acknowledgements}

Our sincere thanks to the Dr.G.S. Rao, Managing Director, Yashoda group of hospitals and Dr.A.Lingaih, Director of Medical services for their generous support to carry out this study in Yashoda Hospital. Hyderabad.

\section{References}

1. Biswas M, Sen S, Simmons J. Etiology and risk factors of ischemic stroke in Indian American patients from a hospital based registry in New Jersey USA. Neurol Asia 2009; 14:81-86.

2. Pilz S, Dobning H, Fischer JF, Wellnitz B, Seelhorst U, Boehm $\mathrm{BO}$ et al. Low vitamin $\mathrm{D}$ levels predict stroke in patients referred to coronary angiography. Stroke 2008;39:2611-2613.

3. Kilkkinen A, Knekt P, Aro A, Rissanen H, Marniemi J, Heliovaara $\mathrm{M}$, et al. Vitamin D status and the risk of cardiovascular disease death. Am J Epidemiol 2009;170:1032-1039.

4. Zhao G, Ford ES, Li C, Croft JB. Serum 25-hydroxy vitamin levels and all-cause and cardiovascular disease mortality among US adults with hypertension; the NHANES linked mortality study. J Hypertens 2012;30:284-289.

5. Kendrick J, Targher G, Smits G, Chonchol M. 25-Hydroxyvitamin $\mathrm{D}$ deficiency is independently associated with cardiovascular disease in the Third National Health and Nutrition Examination Survey. Atherosclerosis 2009;205:255-260.

6. Pasco JA, Henry MJ, Kotowicz MA, Sanders KM, Seeman E, Pasco JR, et al. Seasonal periodicity of serum vitamin D and parathyroid hormone, bone resorption and fractures: the Geelong Osteoporosis Study. J Bone Miner Res 2004:19:752-758.

7. Ono Y, Suzuki A, Kotake M, Zhang X, Nishiwaki-Yasuda K, Ishiwata $Y$, et al. Seasonal changes of serum 25-hydroxy vita- min D and intact parathyroid hormone levels in a normal Japanese population. J Bone Miner Metab 2005;23:147-151.

8. Mallah EM, Hamad MF, Elmanaseer MA, Qinna NA, Idkaidek NM, Arafat TA, et al. Plasma concentrations of 25-hydroxyvitamin D among Jordanians: effect of biological and habitual factors on vitamin D status. BMC Clin Pathol 2011;11:8.

9. Attia A, Emara A, Shoker A. Therapeutic potential of 25-hydroxy vitamin $\mathrm{D}$ in promoting cardiovascular Health. Arab J of Nephrol and Transplant 2010;3:37-46.

10. Holick MF.Vitamin D deficiency. N Engl J Med 2007;357:266281.

11. Harinarayan CV, Ramalakshmi T, Prasad UV, Sudhakar D, Srinivasarao PV, Sarma KV, et al. High prevalence of low dietary calcium, high phytate consumption, and vitamin $\mathrm{D}$ deficiency in healthy south Indians. Am J Clin Nutr 2007;85:10621067.

12. Tharvaldsen P, Asplund K, Kuulasmma K, Rajakangas AM, Schorll M. Stroke incidence case fatality and mortality on WHO MONOCA project. Monitoring Trends and Determinants in Cardiovascular disease Vol 26, World Health Organization; 1995. p. 361-370.

13. Adams JrHP, Bendixen BH, Kappelle LJ, Biller J, Love BB, Gordon DL, et al. Classification of Subtypes of Acute Ischemic stroke Definitions for use in a multicenter clinical trial TOAST. Trial of Org 10172 in Acute Stroke Treatment. Stroke 1993;24: 35-41.

14. Gentry EM, Kalsbeek WD, Hegelin GC, Jones JT, Gaines KL, Forman MR, et al. The Behavioral Risk factor Surveys, II: design, methods and estimates from combined state data. Am J Prev Med 1985;1:9-14.

15. Britov AN, Bystrova MM. New guidelines of Joint National Committee (USA) on prevention, Diagnosis and Management of Hypertension. From JNC VI to JNC VII Kardiologiia 2003; 43:93-97.

16. Kuzuyz T, Nakagawa S, Satoh J, Kanazawa Y, Iwamoto Y, Kobayashi M, et al. Report of the Committee on the classification and diagnostic criteria of diabetes mellitus. Diabetes Res Clin Pract 2002;55:65-85.

17. Radhakrishnamurthy B. Blood Lipid: In Heart Disease. Columbus, GA: Quill publication; 2003. p. 18-27.

18. Glader CA, Boman J, Saikku P, Stenlund H,Weinehall L, Hallmanns $\mathrm{G}$, et al. The proatherogenic properties of lipoprotein(a) may be enhanced through the formation of circulating immune complexes containing Chlamydia pneumoniae specific IgG antibodies. Eur Heart J 2000;21:639-646.

19. Saponsik G, Caplan LR, Gonzalez LA, Baird A, Dashe J, Luraschi A, et al. Differences in stroke subtypes among natives and Caucasians in Boston and Buenos Aires. Stroke 2000;31:2385- 
2389.

20. Radhakrishnamurthy B. Obesity: In Heart Disease. Columbus, GA:Quill publication; 2003. p. 38-44.

21. Nemerovski CW, Dorsch MP, Simpson RU, Bone HG, Aaronson KD, Bleske BE. Vitamin D and cardiovascular disease. Pharmacotherapy 2009;29:691-708.

22. Lee JH, Keefe JHO, Bell D, Hensrud DD, Holick MF. Vitamin $\mathrm{D}$ deficiency an important, common, and easily treatable cardiovascular risk factor? J Am Coll Cardiol 2008;52:1949-1956.

23. Poole KE, Loveridge N, Barker PJ, Halsall DJ, Rose C, Reeve J, et al. Reduced vitamin D in acute stroke. Stroke 2006;37:243245.

24. Sun Q, Pan A, Hu FB, Manson JE, Rexrode KM. 25-Hydroxyvitamin D levels and the risk of stroke: a prospective study and meta-analysis. Stroke 2012;43:1470-1477.

25. Buell JS, Dawson-Hughes B, Scott TM, Weiner DE, Dallal GE, Qui WQ, et al. 25 Hydroxyvitamin D, dementia, and cerebrovascular pathology in elders receiving home services. Neurology 2010;74:18-26.

26. Bonakdaran S, Varsteh AR. Correlation between serum 25-hydroxy vitamin D3 and laboratory risk markers of cardiovascular diseases in type 2 diabetic patients. Saudi Med J 2009;30: 509-514.

27. Carrelli AL, Walker MD, Lowe H, McMahon DJ, Rundek T, Sacco RL, et al. Vitamin D deficiency is associated with subclinical carotid atherosclerosis: the Northern Manhattan study. Stroke 2011;42:2240-2245.

28. Martins D, Wolf M, Pan D, Zadshir A, Tareen N, Thadhani R, et al. Prevalence of cardiovascular risk factors and the serum levels of 25-hydroxyvitamin D in the United States: data from the Third National Health and Nutrition Examination Survey. Arch Intern Med 2007; 167:1159-1165.

29. Zittermann A, Tenderich G, Berthold HK, Korfer R, Stehle P. Low vitamin $\mathrm{D}$ status: a contributing factor in the pathogenesis of congestive heart failure? J Am Coll Cardiol 2003;41:105-112.

30. Kim DH, Sabour S, Sagar UN, Adams S, Whellan DJ. Prevalence of hypovitaminosis D in cardiovascular diseases (from the National Health and Nutrition Examination Survey 2001 to 2004). Am J Cardiol 2008;102:1540-1544.

31. Giovannucci E, Liu Y, Hollis BW, Rimm EB. 25-hydroxyvitamin $\mathrm{D}$ and risk of myocardial infarction in men: a prospective study. Arch Intern Med 2008;168:1174-1180.

32. de Boer IH, Kestenbaum B, Shoben AB, Michos ED, Sarnak MJ, Siscovick DS. 25-hydroxyvitamin D levels inversely associated with risk for developing coronary artery calcification. $J$ Am Soc Nephrol 2009;20:1805-1812.

33. Michos ED, Melamed ML. Vitamin D and cardiovascular disease risk. Curr Opin Clin Nutr Metab Care 2008;11:7-12.
34. Marcén R, Jimenez S, Fernández-Rodriguez A, Galeano C, Villafruela JJ, Gomis A, et al. Are low levels of 25-hydroxyvitamin $\mathrm{D}$ a risk factor for cardiovascular diseases or malignancies in renal transplantation. Nephrol Dial Transplant 2012;27(Suppl 4):iv47-52.

35. Kühn T, Kaaks R, Teucher B, Hirche F, Dierkes J, Weikert C, et al. Plasma 25-hydroxyvitamin $\mathrm{D}$ and its genetic determinants in relation to incident myocardial infarction and stroke in the European prospective investigation into cancer and nutrition (EPIC)-Germany study. PLoS One 2013;8:e69080.

36. Li YC, Kong J, Wei M, Chen ZF, Liu SQ, Cao LP. 1,25-Dihydroxyvitamin $\mathrm{D}(3)$ is a negative endocrine regulator of the renin-angiotensin system. J Clin Invest 2002;110:229-238.

37. Aihara K, Azuma H, Akaike M, Ikeda Y, Yamashita M, Sudo T, et al. Disruption of nuclear vitamin $\mathrm{D}$ receptor gene causes enhanced thrombogenicity in mice. J Biol Chem 2004;279:3579835802 .

38. Watson KE, Abrolat ML, Malone LL, Hoeg JM, Doherty T, Detrano $\mathrm{R}$, et al. Active serum vitamin $\mathrm{D}$ levels are inversely correlated with coronary calcification. Circulation 1997;96: 1755-1760.

39. Merke J, HofmannW, Goldschmidt D, Ritz E. Demonstration of $1,25(\mathrm{OH}) 2$ vitamin D3 receptors and actions in vascular smooth muscle cells in vitro. Calcif Tissue Int 1987;41:112-114.

40. Rigby WF, Denome S, Fanger MW. Regulation of lymphokine production and human $\mathrm{T}$ lymphocyte activation by $1,25-\mathrm{di}$ hydroxyvitamin D3. Specific inhibition at the level of messenger RNA. J Clin Invest 1987;79:1659-1664.

41. Jouni ZE, Winzerling JJ, McNamara DJ. 1,25-Dihydroxyvitamin D3-induced HL-60 macrophages: regulation of cholesterol and LDL metabolism. Atherosclerosis 1995;117:125-138.

42. Nisbet JA, Eastwood JB, Colston KW, Ang L, Flanagan AM, Chambers TJ, et al. Detection of osteomalacia in British Asians: a comparison of clinical score with biochemical measurements. Clin Sci 1990;78:383-389.

43. Preece MA, McIntson WB, Tomlinson S, Ford JA, Dunnigan MG, O’Riordan JL. Vitamin D deficiency among Asian immigrants to Britain. Lancet 1973;1:907-910.

44. Holick MF. Vitamin D: photobiology, metabolism of action, and clinical applications. In: Farus MJ (ed) Primer on the Metabolic Bone Diseases, 4th edn. Lippincott Williams and Wilkins, Philadelphia, 1999; pp 92-99.

45. Lips P. Vitamin D deficiency and secondary hyperparathyroidism in the elderly: consequences for bone loss and fractures and therapeutic implications. Endocrine Rev 2001;22:477-501.

46. Ryu WS, Lee SH, Kim CK, Kim BJ, Yoon BW. Increased serum alkaline phosphatase as a predictor of long-term mortality after stroke. Neurology 2010;75:1995-2002. 
47. den Hertog HM, van Rossum JA, van der Worp HB,van Gemert HM, de Jonge R, Koudstaal PJ, et al. C-reactive protein in the very early phase of acute ischemic stroke: association with poor outcome and death. J Neurol 2009; 256:2003-2008.

48. Di Napoli M, Papa F, Bocola V. C-reactive protein in ischemic stroke: an independent prognostic factor. Stroke 2001;32:917924.

49. Gillor A, Groneck P, Kaiser J, Schmitz-Stolbrink A. Congestive heart failure in rickets caused by vitamin $\mathrm{D}$ deficiency. Monatsschr Kinderheilk 1989;137:108-110.

50. MacLaughlin J, Holick MF. Aging decreases the capacity of hu- man skin to produce vitamin D3. J Clin Invest 1985;76:15361538.

51. Jain V, Gupta N, Kalaivani M, Jain A, Sinha A, Agarwal R. Vitamin $\mathrm{D}$ deficiency in healthy breastfed term infants at 3 months \& their mothers in India: seasonal variation \& determinants. Indian J Med Res 2011;133:267-273.

52. Goswami R, Gupta N, Goswami D, Marwaha RK, Tandon N, Kochupillai N. Prevalence and significance of low 25-hydroxyvitamin $\mathrm{D}$ concentrations in healthy subjects in Delhi. Am J Clin Nutr 2000;72:472-475. 